\title{
The set-size effect in personality impression formation is not an artifact
}

\author{
IRWIN P. LEVIN* \\ University of Iowa, Iowa City, Iowa 52242 \\ and \\ MARTIN F. KAPLAN \\ Northern Illinois University, De Kalb, Illinois 60115
}

\begin{abstract}
The set-size effect in impression formation has been a highly reliable phenomenon when set size was varied as a within-S factor, but this effect has often been absent in between-S designs. Researchers have questioned the use of one or the other of these design techniques and have consequently labeled as artifactual either the presence or absence of set-size effects. This is a crucial matter for theories of impression formation. Studies are cited which have obtained the set-size effect in a paired-comparisons paradigm where previous design criticisms would not seem to apply, and in between-S designs using specific procedural techniques. It is concluded that the set-size effect is not an artifact.
\end{abstract}

The set-size effect in personality impression formation refers to the finding that increasing the number of equal valued, nonneutral stimuli (usually personality-trait adjectives) leads to a more extreme response. An averaging model which assumes that a neutral initial impression is averaged in with the information presented can account for such an effect. More precisely, this model predicts a negatively accelerated set-size curve that agrees closely with data from a number of studies (e.g., Anderson, 1965, 1967).

Sloan and Ostrom (1974) recently catalogued studies dealing with the set-size effect in impression formation. Studies varied in the nature of the stimulus material and in the response scale, but these differences did not appear to be crucial. Set-size effects were found when the same Ss were presented with trait sets of varying size, but exceptions occurred when Ss judged trait sets of only one size. In other words, set-size effects were generally found in within-S designs, but not in between-S designs.

Some investigators have labeled as artifactual the findings in one or the other type of experimental design. Byrne, Clore, Griffitt, Lamberth, and Mitchell (1973) have argued that the within-S designs are prone to demand characteristic problems, while single judgments represent the natural state of attraction. On the other hand, Kaplan and Anderson (1973) suggest that between-S designs are subject to errors due to the relativity of judgment, and to scalar requirements. Each $\mathrm{S}$ may adjust his subjective response scale to the range of stimuli presented, thus attenuating response differences between Ss. Lesser power in between-S designs may also account, in part, for the inability to find reliable set-size effects.

\footnotetext{
*Requests for reprints should be sent to Irwin P. Levin Department of Psychology, University of Iowa, Iowa City, Iowa 52242.
}

The question of whether or not set-size effects are artifactual is of considerable theoretical importance. The existence of a set-size effect required the inclusion of an initial impression in the averaging model of impression formation (Anderson, 1967). However, the importance of a concept such as initial impression has long been recognized in areas such as attitude change. Furthermore, Kaplan (1972) has shown the utility of considering the initial impression as an important parameter of impression formation by relating it to individual differences in processing personality information and in set-size effects. The lack of set-size effects would be damaging to accounts that include the initial impression and would support alternative formulations, such as Byrne's (1971) proportional model of attraction formation.

The paired-comparisons paradigm has received little attention in the study of impression formation but may be relevant to the present issue. On a single trial, Ss are presented with two personality descriptions and are asked, for example, to choose the more likable of the two hypothetical persons. This permits the manipulation of set size within a single choice trial.

A study by Levin, Schmidt, and Norman (1971) directly examined the set-size effect in a paired-comparisons paradigm. Ss received pairs of person descriptions, each pair consisting of two sets with different numbers of isovalent personality-trait adjectives. Ss indicated which person in a pair they would prefer to have as a friend and to what extent. Reliable set-size effects were obtained. For favorable adjectives, Ss preferred the person in the pair described by the larger number of adjectives, and for unfavorable adjectives, Ss preferred the person described by the smaller number of adjectives. The latter finding is important because it rules out the possibility that Ss respond to the cue of differential set size by consistently 
choosing the person described by the larger number of adjectives. Degree of preference varied as a direct function of the difference in set size between the two person descriptions in a given pair. Additional support for a set-size effect in person preference choices is provided by Anderson and Alexander (1971) and Levin and Schmidt (1970).

The existence of a reliable set-size effect in the paired-comparisons paradigm argues for the reliability of this effect in person perception. In the laboratory setting, a given choice should be only minimally affected by previous choices and by scalar response requirements. Furthermore, the process tapped in the paired-comparisons paradigm would seem to be a pervasive one-we are often faced with a choice between two or more political candidates, roommates, tennis partners, etc. The findings here would seem to answer the criticisms of Byrne et al (1973) and Kaplan and Anderson (1973) regarding design characteristics.

The set-size effect thus does not seem to be a judgmental artifact in spite of the difficulty in obtaining such an effect in between-S designs. In fact, recent data suggest that reliable set-size effects can be obtained in between-S designs if certain reasonable procedural features are included. Sloan and Ostrom (1974) increased the sensitivity of the experimental design over that usually employed in between-S manipulations of set size by using a large number of Ss, a large number of experimental and practice judgments per $\mathrm{S}$, and a wide range of set sizes. Kaplan and Major (1973) made differences in set size salient to the Ss by informing them of the possibility of receiving more or less information than the amount actually given. The reliable set-size effect in these studies underscores the importance of the set-size effect as a phenomenon to be accounted for in models of impression formation.

\section{REFERENCES}

Anderson, $\mathrm{N}$. $\mathrm{H}$. Averaging versus adding as a stimulus-combination rule in impression formation. Journal of Experim ental Psychology, 1965, 70, 394-400.

Anderson, N. H. Averaging model analysis of set-size effect in impression formation. Journal of Experimental Psychology, 1967, 75, 158-165.

Anderson, N. H., \& Alexander, G. R. Choice test of the averaging hypothesis for information integration. Cognitive Psychology, $1971,2,313-324$.

Byrne, D. The attraction paradigm. New York: Academic Press, 1971 .

Byrne, D., Clore, G. L., Griffitt, W., Lamberth, J., \& Mitchell, H. E. When research paradigms converge: Confrontation or integration? Journal of Personality \& Social Psychology, $1973,28,313-320$.

Kaplan, M. F. The modifying effect of stimulus information on the consistency of individual differences in impression formation. Journal of Experimental Research in Personality, $1972,6,213-219$.

Kaplan, M. F., \& Anderson, N. H. Information integration theory and reinforcement theory as approaches to interpersonal attraction. Journal of Personality \& Social Psychology, 1973, 28, 301-312.

Kaplan, M. F., \& Major, G. Will you like me at set-size 3 as you might at 6? Amount of information and attraction. Paper presented at the Meetings of the Psychonomic Society, presented at the Meeting, November 1973 .

Levin, I. P., \& Schmidt, C. F. A paired-comparisons paradigm for investigating person perceptions. Psychonomic Science, 1970, 20, 359-361.

Levin, I. P., Schmidt, C. F., \& Norman, K. L. Person preference choices: Tests of a subtractive averaging model. Journal of Experimental Psy chology, 1971, 90, 258-261.

Sloan, L. R., \& Ostrom, T. M. Amount of information and interpersonal judgment. Journal of Personality \& Social Psychology, 1974, 29, 23-29.

(Received for publication December 13, 1973.) 